\title{
DA POLÍTICA À LITERATURA: o percurso de IGNAZIO SiLONe Patricia Peterle
}

\begin{abstract}
O papel do intelectual não é mais o de se posicionar "um pouco à frente e um pouco ao lado" [...]; é antes o de lutar contra as formas de poder ali onde ele é, ao mesmo tempo, o objeto e o instrumento disso: na ordem do "saber", da "verdade", da "consciência", do "discurso". Michel Foucault

Il problema riguarda direttamente tutti quanti non abbiano mai separato l'attività di scrittore da un sentimento di responsabilità sociale. Per quel che mi riguarda, non sono stato mai tentato dalla Torre d'avorio, benché abbia sentito dire che non vi manchino tepore e tranquillità. Ma i modi e soprattutto lo spirito dell' "impegno" devono essere riveduti.
\end{abstract} IgNAZio Silone

Por seus posicionamentos, Ignazio Silone ${ }^{1}$ (1900-1978) pode ser considerado uma das grandes personalidades intelectuais italianas e, até, europeias do século XX. A sua produção literária e ensaística, somada à frequente e assídua correspondência epistolar com outros intelectuais de diferentes nacionalidades, é um dado fundamental para o delineamento do perfil deste escritor. Como coloca Michel Foucault, na epígrafe supracitada, a classe dos intelectuais tem como uma de suas marcas de atuação na sociedade "lutar contra as formas de poder", seja ele aparente ou oculto. Este tipo de ação pode ser identificado em muitos escritores, artistas e homens de cultura que atuaram, sobretudo, na primeira metade do século XX, quando regimes totalitários, de direita e de esquerda, dominaram o cenário político-social e cultural no ocidente. Neste momento, as relaçōes entre literatura e política são muitas e múltiplas, configurando uma trama híbrida, e é nesta imbricada rede que pode ser inserida tanto a produção quanto a trajetória deste escritor italiano.

\footnotetext{
${ }^{1}$ Ignazio Silone é o pseudônimo de Secondino Tranquilli, e depois de 1960 será legalizado.
} 
* [...] estava então com trinta anos: tinha acabado de sair do partido comunista, pelo qual sacrifiquei a minha juventude, os meus estudos e qualquer interesse pessoal; estava gravemente doente; necessitado; não tinha família (fiquei órfão aos quinze anos meu único irmão estava no cárcere, como católico antifascista e, pouco depois, morreu); fui expulso da França e da Espanha; não podia retornar à Itália; em uma palavra, estava à beira do suicídio $[\ldots]$ O meu afastamento da política pôde portanto aparecer à primeira vista uma imposição de circunstâncias exteriores; mas, bem cedo, à medida que em mim ia acontecendo aquele renascimento interior, este tornou-se um distanciamento efetivo da minha consciência de qualquer ambição e cobiça de poder [...] A minha atividade de escritor foi o testemunho daquela luta e maturação interna. Os meus livros são o relato das incertezas, das dificuldades, dos sucessos, da vitória da minha alma, na sua luta contra aquilo que poderia existir de vulgar e meramente instintivo na minha vida precedente. (SILONE, Ignazio. Romanzi e saggi 1927-1944, I Meridiani. Milano: Mondadori, 1999: 1396-1397.)
Nessa perspectiva, refletir sobre as marcas que caracterizam os passos de Ignazio Silone, desde a infância em solo marsicano, na zona do Fucino, até a fase mais madura, depois do exílio e o retorno à Itália, é fundamental para o maior entendimento de seus posicionamentos enquanto indivíduo e intelectual, dos seus escritos e, até, da sua visão de literatura. O percurso desse autor é, de fato, caracterizado por vários acontecimentos, históricos e pessoais: a emigração, ${ }^{2}$ o terremoto de 1915 no centro-sul da península itálica, a fundação do Partito Comunista d'Italia, ${ }^{3}$ em 1921, o fascismo, a clandestinidade, o antifascismo, o exílio, a expulsão do partido, as duas guerras mundiais e os fatos da Hungria são só alguns elementos que dão forma a esta híbrida e complexa trama. Uma rede imbricada de relações entre o vivido e a escritura, entre história e literatura, na qual os processos narrativos exploram e são, de certa forma, dimensionados pelo olhar e pela experiência vivenciada. A escrita para Silone representa um conjunto de necessidades, de expressão, de diálogo consigo mesmo, de comunicação com o outro, e é também a consequência de uma profunda crise existencial em relação ao mundo exterior, a qual o leva quase à beira do suicídio:

[...] avevo allora trent' anni: ero appena uscito dal partito comunista, al quale avevo sacrificato la mia gioventù, i miei studi e ogni interesse personale; ero gravemente malato; ero privo di mezzi; ero senza famiglia (rimasto orfano a quindici anni, l'unico fratello che mi restava era allora in carcere, come cattolico antifascista e, poco dopo morì); ero stato espulso dalla Francia e dalla Spagna; non potevo tornare in Italia; in una parola, ero sull'orlo del suicidio [...] Il mio allontanamento dalla politica poté dunque apparire dapprima un'imposizione di circostanze esteriori; ma ben presto, a mano a mano che in me si compiva quell'interiore rinascita, esso corrispose ad un effettivo distacco dalla mia coscienza da ogni ambizione e bramosia di potere. [...]. La mia attività di scrittura è stata la testimonianza di quella mia lotta e maturazione interna. I miei libri sono il resoconto delle incertezze, delle difficoltà, dei successi, della vittoria della mia anima, nella sua lotta contro quello che poteva esserci di volgare e meramente istintivo nella mia vita precedente. ${ }^{4^{*}}$

A escrita, porém, já fazia parte de algum modo do seu cotidiano. Os inúmeros artigos e as várias colaborações feitas para as

${ }^{2} \mathrm{O}$ fenômeno da emigração foi vivenciado pelo pai e é citado rapidamente em algumas obras.

${ }^{3}$ O Partito Comunista d'Italia mantém este nome até 1943, quando passa a ser denominado de Partito Comunista Italiano.

${ }^{4}$ As traduções do italino para o português são de minha autoria. 
revistas e outras publicações militantes constituíam uma das atividades desenvolvidas por Silone dentro do Partido. ${ }^{5} \mathrm{Na}$ década de 1920, será Antonio Gramsci a perceber e a sinalizar para a sensibilidade do texto siloniano que se diferenciava daqueles outros enviados pelos demais colaboradores do partido. Todavia, a aproximação com a produção literária só vem mais tarde e terá um significado fulcral na trajetória de vida desse intelectual e ex-militante. A aproximação entre Silone e a literatura, na qualidade de escritor, é também o resultado dessa profunda crise existencial, que o abala no início da década de 1930. Internado por causa do grave estado de saúde num sanatório suíço, longe da sua terra e expulso do partido, ele encontra na escrita um modo de dialogar consigo mesmo, rever os passos dados e recuperar os momento significativos de sua trajetória: das lembranças mais familiares - de quando era apenas um menino que estava aprendendo a ler na beirada da porta de sua casa ${ }^{6}$ - até a mudança do campo, Pescina (a terra natal), para a cidade-capital, Roma, passando pelo envolvimento maior com a política e, enfim, a partida para o exílio.

A crise é consequência de uma série de elementos e situações, sendo talvez o principal a ruptura com o partido e o significado deste ato, que não é apenas um afastamento da política e das atividades do partido. Na verdade, essa organização, o Partito Comunista d'Italia, com o tempo, preencheu espaços que antes eram marcados pelas inúmeras ausências e faltas. Como Silone afirma em Uscita di sicurezza (1965), o partido aos poucos se transforma nos três pilares fundamentais: a família, a igreja e o quartel. Laços fortes que quando desfeitos desequilibram uma ordem existente e geram inquietações e, sobretudo, questionamentos e dúvidas, que passam a ser motivados e instigados por um outro olhar, que mesmo estando ainda dentro da organização também já está fora.

Na carta datada de 2 de setembro de 1937,, escrita por Silone, em francês, e endereçada a Rainer Biemel, ${ }^{8}$ ao responder a algumas perguntas, comenta os momentos difíceis devido aos quais passou

\footnotetext{
${ }^{5}$ Dentro e fora do partido, Silone sempre manteve uma assídua colaboração com inúmeros periódicos, dentre os quais: L'Avanti!', Il Lavoratore, L'Avanguardia, La Batalla, Information, La Riscossa, Avvenire dei lavoratori, Europa Socialista, Tempo Presente.

${ }^{6}$ É essa imagem que inicia o primeiro texto de Uscita di sicurezza, uma espécie de livro de memórias, publicado em 1965.

${ }^{7}$ Esta e outras correspondências fazem parte do acervo da Fondazione Turati, em Florença, e do Centro Studi Ignazio Silone, em Pescina.

${ }^{8}$ Rainer Biemel é o editor francês de Pane e vino (1936).
} 
* O escrever nunca foi e não poderia ser para mim, salvo em algum raro momento de graça, um sereno gozo estético, mas a penosa e solitária continuação de uma luta, depois de ter-me separado de companheiros muito queridos. E as dificuldades com as quais me deparo, às vezes, ao expressar-me não proveem de certo da inobservância das famosas regras do belo escrever, mas de uma consciência que custa a cicatrizar algumas feridas escondidas, talvez incuráveis. (SILONE, Ignazio. Uscita di sicurezza. Milão: Mondadori, 2001: 98.) a se afastar da instituição que o tinha acolhido por tantos anos. É importante lembrar, aqui, que o partido que expulsa Silone é o mesmo que ele tinha ajudado a fundar em 1921, em Livorno, ao lado de Antonio Gramsci e Amadeo Bordiga. ${ }^{9}$ Como testemunha nesta correspondência, Silone se vê imerso numa crise física e espiritual, resultado de uma ação contínua de autoquestionamento diante das situações vistas e vivenciadas. A aproximação maior com a arte e o início de uma ativa participação na vida literária são os elementos que vão propiciar o que ele mesmo denomina nesta carta de nouvelle naissance. Isto é, a oportunidade de recuperar a sua "voz", enquanto indivíduo, agora não mais através da organicidade do partido, mas sim por meio de uma reflexão "autônoma" sobre a sociedade, o homem e sua condição num período caracterizado pelos regimes totalitários, como pode ser observado no trecho abaixo:

Lo scrivere non è stato e non poteva essere per me, salvo in qualche raro momento di grazia, un sereno godimento estetico, ma la penosa e solitaria continuazione di una lotta, dopo essermi separato da compagni assai cari. E le difficoltà con cui sono, talvolta, alle prese nell'esprimermi non provengono certo dall'inosservanza delle famose regole del bello scrivere, ma da una coscienza che stenta a rimarginare alcune nascoste ferite, forse inguaribili.

O perfil do ativista político e do intelectual, perseguido pelo regime fascista e expulso mais tarde do partido, não podem, evidentemente, desaparecer da sua produção literária; na verdade, tais contornos ajudam e nutrem o coro do seu discurso. Escrever para Silone se configura, portanto, como uma forma contínua de compreensão e questionamento da realidade que se apresenta ao seu redor. Assim sendo, a literatura para Silone não deve estar pronta ou preparada para dar respostas quando solicitada; ela, como qualquer outro tipo de manifestação artística, pode ser concebida, neste caso, como o resultado de reflexões e inquietações. Continuando nesta linha, é possível ainda afirmar que para Silone a escrita representa uma forma de ação e, até, uma reação diante das problemáticas morais e sociais existentes e vividas.

Se de um lado a literatura pode ser um convite tentador para passar o tempo, deliciando-se com histórias, construções sintáticas e imagéticas, as quais oferecem ao leitor uma especial sensação

\footnotetext{
${ }^{9}$ Com a fundação do Partito Comunista d'Italia, Silone foi membro da Comissão da Federação Juvenil Comunista italiana e participou de alguns encontros em Moscou.
} 
de prazer e deleite, por outro lado, essa mesma expressão artística pode se transformar num canal mais questionador e até doloroso para o indivíduo, um processo de busca e até mesmo de (auto)conhecimento e conscientização de sua inserção no mundo. A visão de Silone, em relação à complexidade do que é chamado de literatura, pode ser identificada em vários momentos e em vários escritos, como, por exemplo, no texto "La fine di un concordato", publicado no periódico $I l$ Mondo,${ }^{10}$ no qual Silone diz que uma obra literária é uma consequência da experiência de quem a cria e não pode se configurar ou se limitar a um simples instrumento de propaganda política. Da política à literatura e retorno, duas formas e canais diferentes para a expressão de posicionamentos diante do real vivido. Porém, o retorno não é marcado por uma ação política, e sim por uma série de problemáticas e dúvidas que também estão presentes em seus textos literários ou não. Os três primeiros romances, publicados no exílio, Fontamara (1933), Pane e vino ${ }^{11}$ (1936) e Il seme sotto la neve (1941), ${ }^{12}$ configuram-se todos como organismos interrogadores que impõem ao próprio escritor a função de questionador de fatos e da realidade que o cerca. Uma ação, a de refletir e, ao mesmo tempo, problematizar, que é colocada e passada também para o leitor mediante a leitura da obra.

Os títulos dessas obras por si só já são muito representativos: Fontamara* é um neologismo, formado por duas palavras fonte e amara, fonte amarga, que é uma alegoria de todas as desventuras vivenciadas pelos habitantes dessa aldeia fictícia: a falta de luz, a mudança do curso do córrego, a falta de informação e de liberdade para falar, cenas chegam ao clímax no episódio da prisão do protagonista Berardo. ${ }^{13}$ Uma outra imagem que congrega e simboliza as inúmeras ausências vivenciadas pelos fontamareses é aquela da fonte na praça, quando um grupo de mulheres chega à cidade para protestar contra a mudança do curso do córrego. Quando os membros do grupo se aproximam da fonte, na praça, para beber

\footnotetext{
${ }^{10}$ Publicado na edição de agosto de 1940.

${ }^{11}$ Em 1954 Pane e vino é detalhadamente revisto por Ignazio Silone, e passa a ter o título Vino e pane, como confirma a carta enviada pelo autor a seu editor Alberto Mondadori em 06 de novembro do mesmo ano.

${ }^{12}$ Esses três romances caracterizam o que pode ser chamado de primeira fase do autor.

${ }^{13}$ A cenas que se passam na prisão romana podem ser analisadas pela ótica da prisão vista como a representação máxima do uso e do abuso de poder, como coloca Michel Foucault em Microfisica do Poder (2003).
}

(SILONE, Ignazio. Fontamara. Milão: Mondadori, 1985.) 
* (SILONE, Ignazio. Vino e pane. Milão: Mondadori, 1996.)

um pouco de água, depois da longa caminhada, a água desaparece. Mas, a partir do momento em que eles se distanciam, a água volta à fonte. Um vai-e-vem, no qual a água, uma substância necessária à vida humana, é tolhida a este grupo; da mesma forma que lhes são tolhidas a liberdade de pensar e de se expressar. Pane e vino ${ }^{14^{*}}$ é um título composto pelos dois elementos essenciais da mesa de um italiano, que significam aqui a urgência de uma comunhão e de uma renovação. Tal renovação também está presente na figura do protagonista, Pietro Spina, um revolucionário que vivenciou muitas coisas, mas que agora está com um grave problema de saúde e tem de viver na clandestinidade. Para muitos críticos, como Vittoriano Espósito, ${ }^{15}$ este personagem apresenta marcas e reelabora a própria experiência do autor. Il seme sotto la neve é um título, por sua vez, muito significativo: uma semente pode gerar algum fruto sob a neve? Seria essa uma alusão àquele momento histórico-cultural? Pietro Spina, de Pane e vino, reaparece neste livro e continua como protagonista.

A vontade de comunicar, de problematizar e de tornar público seus questionamentos se expressa não só na concretização da obra, mas também nas inúmeras dificuldades enfrentadas para a sua publicação e comercialização. Fontamara, para dar só um exemplo, é escrito em 1930 e publicado primeiramente em língua alemã em 1933, mas só chega ao mercado editorial italiano em 1947, por meio da pequena editora Faro; após dois anos, em 1949, recebe uma revisão do próprio autor e passa a ser editado pela Mondadori. ${ }^{16}$ A Oprecht é a primeira editora, portanto, a publicar o romance e os custos desta publicação são pagos a partir da encomenda antecipada de oitocentos exemplares. Sem grandes pretensōes, este romance leva as dúvidas, perplexidades e a "voz" de Ignazio Silone para vários países. Em pouco tempo, o livro passa a ser considerado um best-seller, obtendo leitores dentro e fora da Europa.

\footnotetext{
${ }^{14}$ Entre 1937 e 1947 é traduzido em mais de vinte línguas e recebe críticas positivas de: T. Mann, R.j. Humm, J.p. Samson, E. Muir, Ph. Ahy, A. Kazin, M. Vaussard, E. Gonzales Lanuza e S. Brodzki.

${ }^{15}$ Para uma leitura mais detalhada ver: Esposito, V. Lettura di Ignazio Silone. Roma: Edizioni dell'Urbe: 1985.

${ }^{16}$ Mas, mesmo antes, o livro já tinha uma edição inglesa em língua italiana e circulava de forma clandestina, tanto na península como em outros países. Deve ser lembrado que não só Fontamara, mas também outros romances, tem várias versões até chegar àquela definitiva.
} 
Em cinco anos, somam-se mais de 29 traduções e mais de um milhão e meio de cópias vendidas. ${ }^{17}$

Em Fontamara e nos outros dois romances escritos e publicados no exílio suíço, que também circularam de forma clandestina pelo território italiano, o que pode ser identificado em comum é a temática fascista, ou melhor antifascista, e a luta pela liberdade de pensamento e de ação que estão presentes na construção de alguns cenários, no perfil de personagens e ainda nas entrelinhas de algumas falas.

O discurso literário pode ser concebido, então, neste contexto, como um canal de interação e comunicação com a sociedade ${ }^{18}$ e, ainda, uma forma de o autor manter uma voz "ativa", num momento em que muitas eram silenciadas e outras programaticamente abafadas. Todavia, não é por apresentar temas ligados a questões políticas e sociais ${ }^{19}$ que a produção siloniana pode ser caracterizada ou vista como uma literatura panfletária. É o próprio Silone, depois do exílio, em 1946, numa entrevista a Gabriele Armandi, então responsável pela redação do jornal Voce Adriatica, que reflete sobre a relação entre política e literatura em suas obras, indicando caminhos até então não percorridos pela crítica literária italiana: ${ }^{20}$

[...] L'errore iniziale di alcuni critici fu di ritenere i miei libri in funzione di propaganda. [...] Si legge per distrarsi. Ma che anche in Italia vi siano lettori avidi di altro e per i quali la letteratura è un nutrimento indispensabile dell'anima, è prodotto dal successo di certe traduzioni da lingue estere."

\footnotetext{
${ }^{17}$ A esse respeito é interessante consultar a carta de Giuseppe Prezzolini, de 4 de outubro de 1934, endereçada ao editor Oprecht, na qual ele mostra a curiosidade e pergunta informações sobre a repercussão e o sucesso de Fontamara. A resposta é escrita em 26 de outubro do mesmo ano por Silone, que afirma que Fontamara já conta com 19 edições em 18 línguas: alemão, italiano, holandês, flamengo, dinamarquês, norueguês, sueco, tcheco, húngaro, romeno, esloveno, croata, hebraico, francês, inglês e espanhol. Ao final da carta, Silone acrescenta, ainda, a seguinte informação "Outras traduções, entre as quais em esperanto, estão programadas". Em relação à circulação desse livro no Brasil, há uma outra carta de 05 de outubro de 1935, enviada por um remetente não identificado de São Paulo, na qual se confirmam a "comercialização" e o sucesso do livro.

${ }^{18}$ É importante lembrar aqui que a primeira experiência literária, Fontamara, é escrita sim no exílio suíço, mas no sanatório em Davos, num momento em que o autor se encontrava isolado e distante "do mundo".

${ }^{19}$ Esses temas, na completude da obra, podem ser vistos como elementos motivadores da mesma, mas a obra não se limita e se delimita neles.

${ }^{20}$ A crítica italiana da época dividia-se em dois eixos: um caracterizado pelo silêncio e outro que rotulava as obras de Silone como panfletárias e, logo, sem valor literário ou artístico.
}

* [...] O erro inicial de alguns críticos foi o de considerar os meus livros como uma forma de propaganda. [...] Lê-se para distrair-se. Mas que também na Itália existam leitores ávidos por outra coisa e para os quais a literatura é um nutrimento indispensável da alma, é consequência do sucesso de certas traduções de línguas estrangeiras. (ARMANDI, Gabriele. Voce Adriatica, 1978, 26). 
*(“Em certo sentido digo que há uma tensão entre o romance e o Estado, que em alguns momentos é muito visível e que, em outros casos, é necessário decifrar". PIGLIA, Ricardo. Critica e ficcion. Barcelona: Editorial Anagrama, 2001: 191.)
Nesta entrevista, Silone aponta para o engano cometido pela crítica, provavelmente por uma primeira e parcial leitura: aquele de ter interpretado a sua escrita como uma simples propaganda ou uma forma de panfleto sem considerar o valor literário intrínseco. Dando continuidade, ele coloca ao lado da fruição uma outra "função" da literatura: a de nutrir a alma do leitor. E é nesta perspectiva que a sua produção também pode ser concebida, pois a obra siloniana pode ser vista como um meio para o diálogo e para a reflexão. É importante, aqui, recuperar uma outra correspondência, endereçada a Rainer Biemel, datada de 2 de setembro de 1937, na qual o escritor italiano afirma que a propaganda não é a sua preocupação e que no trabalho de escritura, ao re-criar um mundo ou um cenário na ficção, ele imprime a estes uma visão, que por sua vez, ressemantiza aquilo que é vivenciado no plano do cotidiano. Assim, certos elementos que, à primeira vista, são ilegíveis no cotidiano, dada a correria, as tensões e os véus existentes - que encobrem e distorcem a visão -, podem se tornar mais claros e mais legíveis por meio do discurso ficcional. É por isso que para Silone o artista é também, mesmo sem querer, um educador.

Num regime totalitário, como o fascismo, que cria e recria fantasias necessárias à sua sobrevivência, que, por sua vez, são apresentadas como "legítimas verdades", o escritor, ou melhor, o intelectual tem um papel primordial: o de tentar descortinar essa realidade que se apresenta sob múltiplos véus e esse poder que é muitas vezes "oculto". Neste sentido, para Silone, o autor pode ter um papel central na sociedade, na medida em que a partir da escrita e seus mecanismos discursivos, pode tentar mostrar uma outra versão da "realidade" por meio da ficção. É neste sentido que Ricardo Piglia coloca o foco na tensão existente entre duas ficçōes: "En cierto sentido yo digo que hay una tensión entre la novela y el Estado, que en algunos momentos es muy visible y que, en otros casos, es necesario descifrarla." ${ }^{\prime \prime}$ É nessas dobras, às vezes mais claras outras mais obscuras, em que se insere a produção ficcional de Silone. ${ }^{21}$ É, ainda, no seio desta tensão que pode ser recuperada a pergunta do crítico Giuseppe Petronio (2000): Quantos são ou foram aqueles que tiveram a coragem de enfrentar perseguiçóes e resistiram ao silêncio ao redor da própria obra e do próprio nome? Um silêncio experienciado por Silone na terra natal, mas quebrado por um

${ }^{21}$ Com efeito, as temáticas apresentadas por este escritor dialogam com o momento histórico-cultural de sua produção e publicação e tendem a ser uma das vozes colocadas no campo de tensão do que é dito e ocultado. 
vasto coro no exterior, composto de traduçôes, resenhas e artigos críticos. Contudo, é no final da década de 1960, com a publicação de Uscita di Sicurezza, ${ }^{*}$ que os primeiro estudos de Luce D’Eramo ${ }^{22}$ começam a romper com o silêncio italiano. ${ }^{23}$

Esse papel de “educador”, citado acima, pode ser visto, então, não como uma função formativa, mas sim como a de um "mediador" que propõe reflexões, dúvidas e problemáticas. O esforço e os obstáculos enfrentados para a publicação de suas obras (em particular para a primeira, como já mencionado) somados ao empenho e ao acompanhamento de todo o processo de edição, desde o contato com editores e até com os tradutores, demonstram o quanto era significativo e importante torná-las públicas e fazer com que as mesmas fossem divulgadas. Na entrevista de 11 de abril de 1954, concedida à revista La Fiera Letteraria, Silone responde a perguntas sobre o seu ofício de escritor:

Perché scrivi? Per comunicare

A quali lettori pensi di preferenza, mentre scrivi? A uomini, a donne solitari, disposti a riflettere e inquieti.

Cosa pensi di offrirgli con i tuoi libri? Un po' di compagnia.

$E$ ai lettori occasionali? Una pulce nell'orecchio*

Estabelecer canais de comunicação, oferecer um pouco de companhia e, em alguns casos, inquietar e colocar uma pulga atrás da orelha são algumas das intenções e até das funções do "educador" e do mediador, enquanto homem de cultura e escritor. A ânsia e a urgência de contar e narrar nascem das perturbações provocadas pela inserção num mundo onde o escritor, pela atividade

${ }^{22}$ Todavia, isto não significa que antes dos estudos de D’Eramo a obra de Silone não tenha recebido críticas positivas. Artigos, textos e programas da Rai de Geno Pampaloni (1949), Giorgio Petrocchi (1949), Guglielmo Petroni (1949) e Goffredo Bellonci (1951) são só alguns exemplos.

${ }^{23}$ Como afirma Vittoriano Esposito, Silone é um caso italiano. Após o silêncio duradouro, o nome do escritor é trazido, no final da década de 1990, para as primeiras páginas dos maiores jornais italianos com a acusação de que ele tinha sido um espião da polícia fascista (OVRA) infiltrado no Partido Comunista. De qualquer modo, essa suspeita apresenta-se inválida, não só pela metodologia apresentada nos livros de "acusação", mas também pelos depoimentos de intelectuais como Norberto Bobbio, Indro Montanelli e estudiosos como Vittoriano Esposito, Sergio Soave e Giuseppe Tamburrano, que apontaram para a não sustentação dessa hipótese. Alguns livros a esse respeito são: BIOCCA, Dario; CANALI, Mauro. L'informatore: Silone, i comunisti e la polizia. Diegaro di Cesena: Luni, 2000; BIOCCA, Dario. Silone. La doppia vita di un italiano. Milano: Rizzoli, 2005; TAMBURRANO, Giuseppe. Il "caso Silone". Torino: UTET, 2006; TAMBURRANO, Giuseppe. Processo a Silone. La disavventura di un povero cristiano. Bari: Lacaita, 2001.
* (SILONE, Ignazio. Uscita di Sicurezza. Milano: Mondadori, 2001.)

* Por que escreve? Para comunicar

Em quais leitores pensa em particular, enquanto escreve? Em homens, em muIheres, dispostos a refletir e inquietos.

O que acha que pode oferecer-Ihes com os seus livros? Um pouco de companhia.

E para os leitores ocasionais? Uma pulga atrás da orelha.

(SILONE, Ignazio. Romanzi e saggi 1945-1978. Milão: Mondadori, 1999: 1212) 
* (HOBSBAWM, Eric (org.). História do Marxismo. Rio de Janeiro: Paz e Terra, 1987: 262)

* (BAUMAN, Zygmunt. La decadenza degli intellettuali: da legislatori a interpreti. Torino: Bollati Boringhieri, 1992.) que exerce, além de tratar do que vê e da sociedade em que vive, pode, também, assumir um outro papel: o de engajar-se e, até, posicionar-se diante de determinadas questóes, as quais, muitas vezes, transcendem a esfera individual. Nessa perspectiva, a escrita pode, ainda, se configurar como um canal a mais, capaz de propiciar outras formas de entendimento e interação com a realidade.

Ignazio Silone, assim como tantos outros escritores de sua época, tem uma estreita relação com a cultura e com a política. Indubitavelmente, no período marcado pelas duas guerras mundiais e pelos regimes totalitários de direita e de esquerda, para qualquer escritor que se declarasse intelectual, era praticamente impossível não ter um posicionamento acerca dos acontecimentos de sua cidade, de seu país e, até, de seu continente. E como bem lembra Hobsbawm:

Independentemente do país de origem, portanto, os intelectuais marxistas que não estavam excluídos do mundo tendiam a ser coparticipantes de uma cultura internacional de esquerda, que arrolava inúmeros escritores e artistas levados a se identificar com o comunismo ou, pelo menos, com o compromisso na luta antifascista: Malraux, Silone, Brecht (apesar de ainda não muito famosos naqueles anos), García Lorca, Dos Passos, Eisenstein, Picasso*

Ao discutir sobre a questão do escritor e da sua função de intelectual na sociedade, Silone coloca dois pontos fundamentais: o sentimento de responsabilidade e a reflexão sobre a condição humana, contemplando nos dois planos uma descida da "torre de marfim". ${ }^{24}$ A delicada nuance destas imbricadas relações, consequentemente, está na atitude constante do intelectual que duvida, reflete; um comportamento que muitas vezes pode até aproximá-lo de um não lugar. Desta forma, posicionar-se diante do mundo e não ignorá-lo são duas atitudes inerentes ao intelectual que deve estar atento para aquilo que o rodeia. Todos esses traços podem delinear e levar à definição do "intérprete", dada por Zygmunt Bauman:* isto é, um homem de cultura e letras, que já não vive, como no passado, circunscrito por uma cápsula invisível e isolado em uma torre de marfim. Ele, o “intérprete”, modelo de intelectual no século XX, possui as vestes de um trabalhador social que tem como função compreender e interpretar, ao invés de julgar e condenar os fatos que se manifestam na sociedade, com um olhar de cima para baixo.

À medida que a página é tecida, o escritor direta ou indiretamente vai se incumbindo de uma tarefa, ou, melhor dizendo,

${ }^{24}$ Ver o texto publicado em La Fiera letteraria de 3 de julho de 1947. 
de uma empreitada: a criação de um canal de comunicação com o leitor. É por meio da construção desse canal que a obra literária se concretiza e tem a possibilidade de oferecer ao leitor um diálogo, onde decifrar e interpretar são as duas palavras-chave. Um período, o das décadas de 1930 e 1940, caracterizado e, sobretudo, marcado pelo panorama histórico-cultural e pela experiência do vivido, que parece reforçar as relações entre política e as manifestações culturais, dentre as quais a própria literatura. Como afirma George Orwell, num texto onde cita o nome de Silone ao lado dos de Arthur Koestler e Grahm Greene:

Em nossa própria época, um escritor sério não pode ignorar a política tal qual faria no século XIX. Os eventos políticos afetam-no muito intimamente, e ele tem plena consciência do fato de que seus pensamentos aparentemente individuais são um produto de seu ambiente social.

O que se apresenta é, portanto, uma densa trama onde política e literatura confluem e se misturam.

\section{Patricia Peterle}

É doutora em Estudos Literários Neolatinos pela UFRJ. Professora do Departamento de Língua e Literatura Estrangeiras e da PósGraduação em Estudos da Tradução e em Literatura da Universidade Federal de Santa Catarina (UFSC). É uma das editoras do suplemento cultural Mosaico e da Coleção Mosaico Italiano da Editora Comunità Italiana. Atua nas áreas de Literatura Comparada e Literatura Italiana. Publicaçôes mais recentes: Livros organizados Nas malhas da narratividade - ensaios sobre literatura, história, teatro e cinema (com Cairo, Luiz Roberto Velloso, et alli (orgs.). Assis: UNESP-Publicações, 2007), "Espaços geográficos e alegóricos nos anos do fascismo" (com Oliveira, Ana Maria D. de., et alli (org.); Visóes poéticas do espaço - ensaios. Assis: UNESP-Publicações, 2008); Interviste su Silone, Pomilio e Flaiano. Pescina: Centro Studi IG, 2009. (com Simone Gambacorta).

\section{Resumo}

A primeira metade do século $\mathrm{XX}$ pode ser perfilada por inúmeros acontecimentos histórico-políticos e culturais que influenciaram toda uma geração de escritores, artistas e intelectuais. É nesta complexa trama que se (inter)relacionam os binômios história e literatura e literatura e política, e nela podem ser inseridos a produção intelec-
* (ORWELL, George. Literatura e Política: jornalismo em tempos de guerra. Rio de Janeiro: Jorge Zahar, 2006: 222.)

Palavras-chave: Literatura italiana; Ignazio Silone, literatura e política; escritorintelectual; papel do intelectual. 
tual e o percurso de Ignazio Silone. Os escritos literários e não desse autor italiano refletem a sua inserção no mundo e a experiência do vivido, que são também caracterizadas pelos regimes totalitários, pelo fascismo, pelo antifascismo e pelo exílio. Marcas de uma existência que permeiam e nutrem o discurso literário siloniano.

Key words: Italian Literature; Ignazio Silone; literature and politics; writer-intellectual; role of the intellectual.

Parole-chiave: Letteratura italiana; Ignazio Silone; letteratura e politica; scrittoreintellettuale; ruolo dell'intellettuale.

\section{Abstract}

The first half of the XX century can be examined through political, historical and cultural events that influenced the whole generation of writers, artists and intellectuals. In this complex fabric are intertwined the binomials history and literature and literature and politics, in which can be inserted the trajectory of Ignazio Silone. His intellectual production reflects his insertion in the world and the experience of the experienced in life, which also bear the mark of totalitarian regimes, fascism, antifascism and by exile: marks of an existence that permeate and nourish Silone's literary speech.

\section{Sommario}

La prima metà del XX secolo è segnata da innumerevoli avvenimenti storico-politici e culturali i quali influenzarono tutta una generazione di scrittori, artisti e intellettuali. È in questa complessa trama che si intrecciano i binomi storia e letteratura e letteratura e politica, ed in essa possono essere inseriti sia la produzione intellettuale sia il percorso di Ignazio Silone. Gli scritti letterari e no di questo autore riflettono il suo inserimento nel mondo e l'esperienza del vissuto, que sono anche caratterizzati dai regimi totalitari, dal fascismo, dall' antifascismo e dall'esilio. Orme di un'esistenza che penetra e nutre il discorso letterario siloniano. 